\title{
The Virtuous Circles of Clinical Information Systems: a Modern Utopia
}

\author{
P. Degoulet ${ }^{1,2}$ \\ 1 Public Health and Medical Informatics Department, Paris Descartes University, France \\ 2 INSERM UMR S 1138 team 22: Information Sciences to support Personalized Medicine, Paris, France
}

\begin{abstract}
Summary
Context: Clinical information systems (CIS) are developed with the aim of improving both the efficiency and the quality of care. Objective: This position paper is based on the hypothesis that such vision is partly a utopian view of the emerging eSociety. Methods: Examples are drawn from 15 years of experience with the fully integrated Georges Pompidou University Hospital (HEGP) CIS and temporal data series extracted from the data warehouses of Assistance Publique - Hôpitaux de Paris (AP-HP) acute care hospitals which share the same administrative organization as HEGP. Three main virtuous circles are considered: user satisfaction vs. system use, system use us. cost efficiency, and system use vs quality of care.

Results: In structural equation models (SEM), the positive bidirectional relationship between user satisfaction and use was only observed in the early HEGP CIS deployment phase (first fou years) but disappeared in late post-adoption ( $\geq 8$ years). From 2009 to 2013, financial efficiency of 20 AP-HP hospitals evalvated with stochastic frontier analysis (SFA) models diminished by $0.5 \%$ per year. The lower decrease of efficiency observed between the three hospitals equipped with a more mature CIS and the 17 other hospitals was of the same order of magnitude than the difference observed between pediatric and non-pediatric hospitals. Outcome quality benefits that would bring evidence to the system use vs. quality loop are unlikely to be obtained in a near future since they require integration with population-based outcome measures including mortality, morbidity, and quality of life that may not be easily available.

Conclusion: Barriers to making the transformation of the utopian part of the CIS virtuous circles happen should be overcome to actually benefit the emerging eSociety.
\end{abstract}

\section{Keywords}

Evaluation of clinical information systems; return on investment; outcome research; acceptance models; information system success criteria

Yearb Med Inform 2016:256-63

http://dx.doi.org/10.15265//Y-2016-030

Published online November 10, 2016

\section{Introduction}

Clinical/hospital information systems $(\mathrm{CIS} / \mathrm{HIS})^{1}$ are widely used all over the world to the benefits of both the institutions that deploy them and the patients whose healthcare is increasingly dependent on the right and efficient use of electronic health records (EHRs), computerized provider order entry systems (CPOE), and adequate clinical decision support systems (CDSSs) [1, 2]. EHR maturity models such as HIMSS analytics EMRAM (Electronic Medical Record Adoption Model) are becoming standards for deployment strategies and benchmarking among institutions that have embraced information technology (IT) solutions [3]. In the United States of America, the meaningful use (MU) legislation that provides government subsidies when the adequate use of IT solutions is demonstrated has had a tremendous effect on the rapid diffusion of certified EHR solutions [4]. For example, in the fourth quarter of $2015,31.3 \%$ of the 5,454 US hospitals studied had reached Stage 6 or 7 of the HIMSS-EMRAM maturity model [3].

Even if they share most CIS objectives, stakeholders are likely to have different perceptions of the main clinical information success and failure criteria as shown in table 1. Health care professionals need to perceive the clinical benefits of a system they are required to use daily when taking care of their patients. Managers will invest and/or continue to invest if they receive sufficient evidence of a financial return on

This paper is the written version of the address given at the 2015 MEDINFO meeting during the François Grémy IMIA award ceremony. It partly reuses and extends with permission material previously published in [1]. investment (ROI). Such financial return is expected from improved health professionals' work-flow management, suppression of order transcription costs, reduced length of stays, reduced duplicated actions, improved communication between stakeholders, and better financial recovery from third party payers [2, 5-10]. From an academic point of view, a CIS should foster clinical research (e.g., through better patient inclusion in public and privately sponsored clinical trials) and accelerate publication of novel outcomes in peer-reviewed journals.

Obviously all these factors are strongly interrelated and it is possible to assume that interactions and interdependencies occur around at least four virtuous circles of success as shown in figure 1. Virtuous cycles refer to complex chains of events which reinforce themselves through a positive feedback loop.Satisfied CIS end-users are supposed to better use the CIS and enter in a win-win strategy with their CIS provider, e.g. by actively participating to user groups and/or by suggesting permanent improvements. Adequately used CISs are likely to improve the quality of care through improved processes and reduced medical errors and to foster process improvements (e.g., through better decision support tools). Money earned by improved financial management can reduce the cost of care but may also be partially reinvested into quality management through progressively enhanced CISs. Within these loops, managers find good reasons to invest and vendors to sell.

To what extent can these virtuous circles be supported by actual data? The conclusions of this article are built from EHR experiences drawn from the deployment and use of a CIS at the Georges Pompidou University Hospital (HEGP), a HIMSS level 6 hospital in Paris, and the university acute 
Table 1 Actor's points of view on CIS success/failure.

$\mathrm{ROI}=$ Return on investment

\begin{tabular}{|l|l|l|}
\hline Point of view & Success & Failure \\
\hline Health professionals & Satisfaction & Dissatisfaction \\
& Use & Rejection \\
Patients & Improved outcomes & Decreased outcomes \\
& Reduced medical errors & Increased medical errors \\
Managers & Better eGovernance & Lack of eGovernance \\
& (Financial) ROI & (Financial) loss \\
Academic & Increased publication rate & No added value \\
& Clinical research funding & Research opportunity loss \\
\hline
\end{tabular}

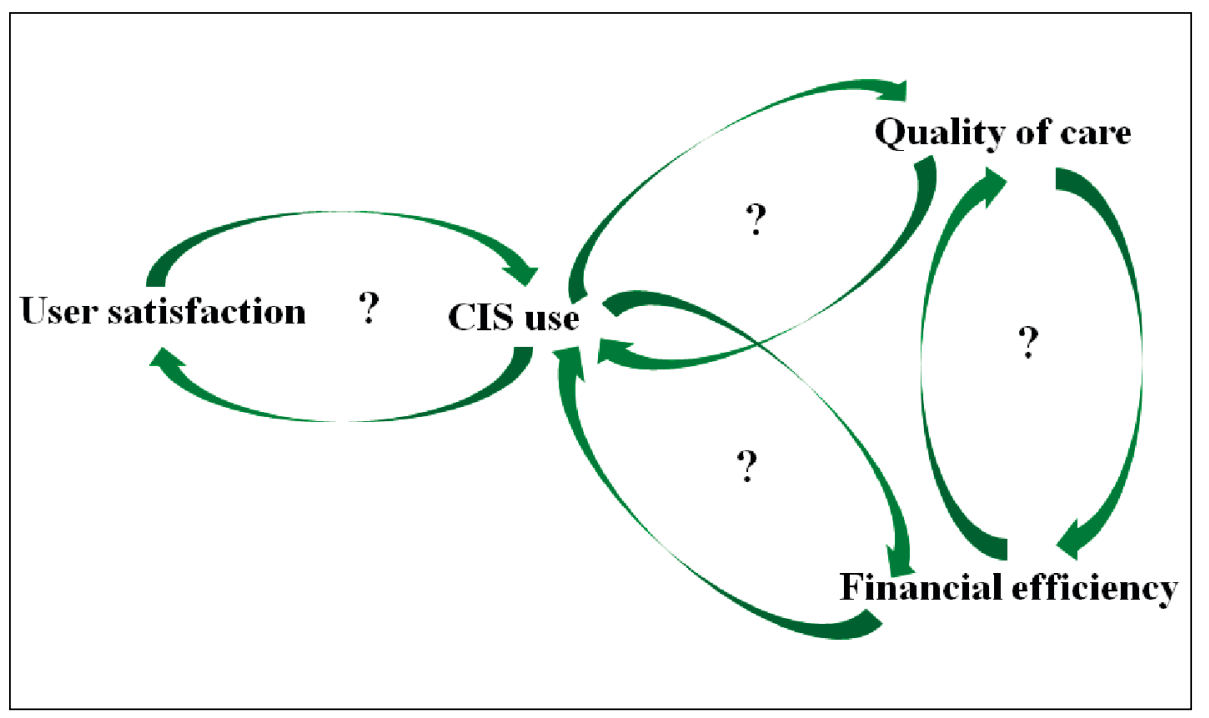

Fig. 1 Four virtuous cycles of clinical information systems. Adapted from [1].

care hospitals sharing the same AP-HP (Assistance Publique - Hôpitaux de Paris) administration [12]. The hypothesis of this article is that the virtuous loops promoted by health professionals, political decision makers, and vendors could be part of a modern but hopefully productive utopia [6] within a truly emerging eSociety. Our objective is not to derive definitive conclusions from a single hospital experience (HEGP) or environment (AP-HP) but to pave the way to more collaborative and international global CIS/HIS evaluations that could test our utopia hypothesis.

\section{The Satisfaction-Use Circle}

Continuous evaluation of end-user satisfaction and CIS use is an essential part of any information system project $[13,14]$. It needs to be performed at each phase of a CIS project, i.e., before installation, during the deployment phase, and later at the consolidation and meaningful use (MU) stages when all users are supposed to adequately use all CIS components and major usability flaws have been corrected $[15,16]$. It should be integrated into a more global evaluation strategy including outcome measures as well as financial ROI.
Evaluation should rely on validated models based on sets of criteria grouped around several evaluation dimensions. Examples of frequently used models include the Information System Success Model (ISSM) of DeLone and McLean [17, 18], the Davis Technology Acceptance Model (TAM) with its extensions (TAM2, UTAUT) [19-21], and the Bhattacherjee Expectation Confirmation Model (ECM) of information system continuance [22]. Data recording can be achieved through group interviews, questionnaires, or ethnographic studies including video recording, or a combination of these methods.

The selected dimensions and their importance depend on the deployment stage of the information system to be evaluated [15]. In the earliest CIS deployment phases, it is important to observe professional users as close as possible to their working environment in order to evaluate their ease of using the CIS and the interaction process (i.e., system usability), as well as the CIS performance, the quality of the initial training, the quality of support (e.g., materials' repair or bug corrections), and to a more general extent how the CIS addresses end-users' expectations. In a CIS MU phase, satisfaction might depend on the personal characteristics of end-users, the quality of the system, and its flexibility to adapt to the changes required by well-trained end-users [16].

Figure 2 illustrates the dimensions retained to evaluate the HEGP CIS since the opening of the hospital in July 2000 [1416] and the associated research hypotheses around the unified model of information system continuance (UMISC) developed during this process [16]. Hypothesis $\mathrm{H}_{13}$ and $\mathrm{H}_{14}$ correspond to the satisfaction-use loop described above. Individual characteristics are considered moderators and include age, sex, and medical profession $\left(\mathrm{H}_{\mathrm{a}}\right.$ to $\left.\mathrm{H}_{\mathrm{d}}\right)$. Six successive electronic evaluation surveys were performed in 2004, 2008, 2011, and every year since 2013.

Surveys were based on self-administered questionnaires consisting of 51 to 58 questions. Self-reported CIS use was assessed for each of the 12 to 18 functions considered. One to seven Likert scales $(1=$ not available, not used or not appropriate, 2 = very rarely, 3 = rarely, $4=$ occasionally, $5=$ rather frequently, $6=$ frequently, $7=$ very frequently) were used for CIS use-related evaluation questions. 


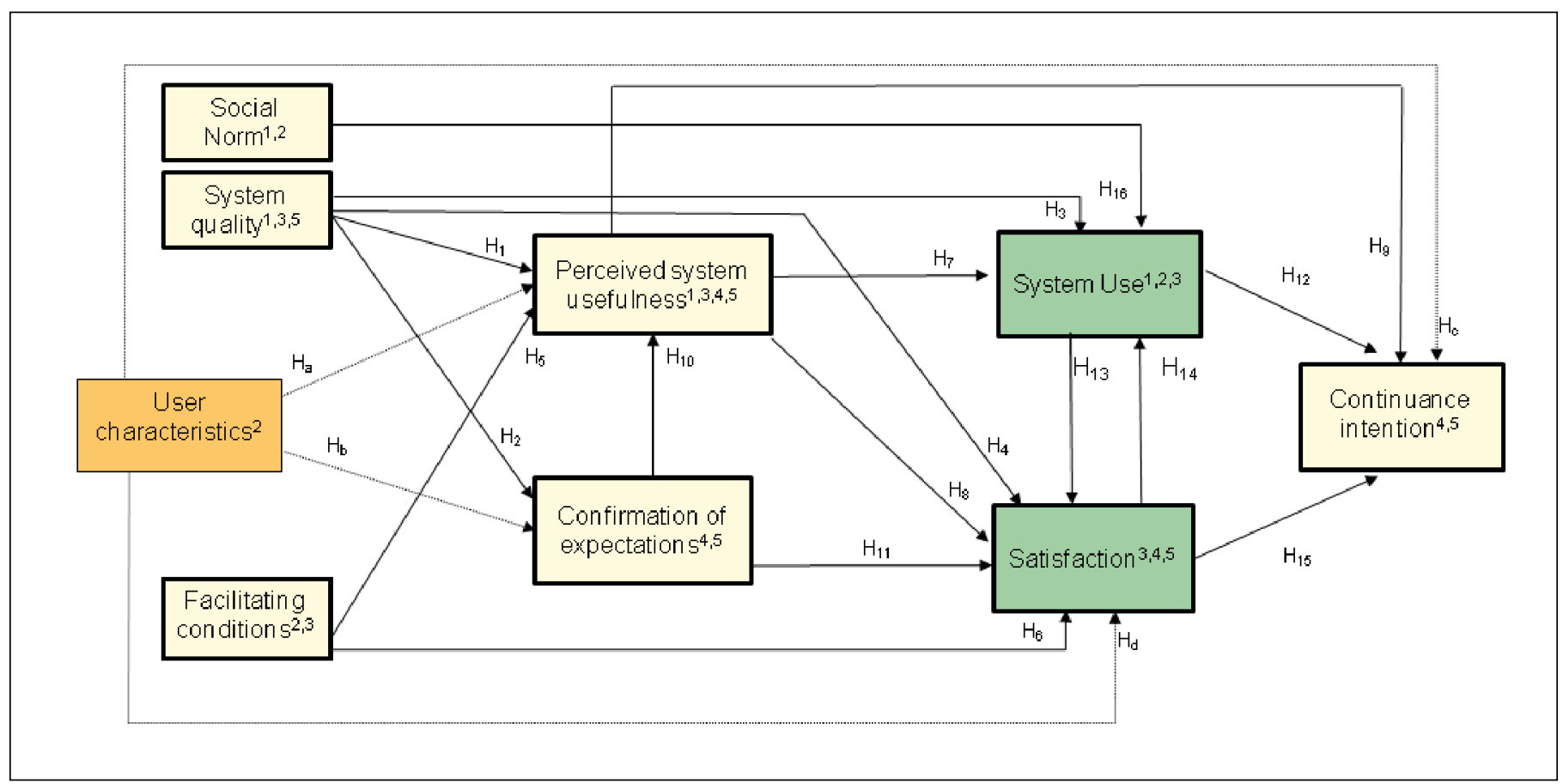

Fig. 2 The Unified Model of Information System Continuance (UMISC) developed at HEGP (Source: [16]). Evaluation dimensions are selected from previously validated models. $1=$ Technology Acceptance Model 2 (TAM2) $[19,20], 2$ = Unified Theory of Acceptance and Use of Technology (UTAUT) [19-21], 3 = Information System Success Model (ISSM) [17], 4= Expectation Confirmation Model (ECM) [22], $5=$ Information Technology Post Adoption Model (ITPAM) [14]

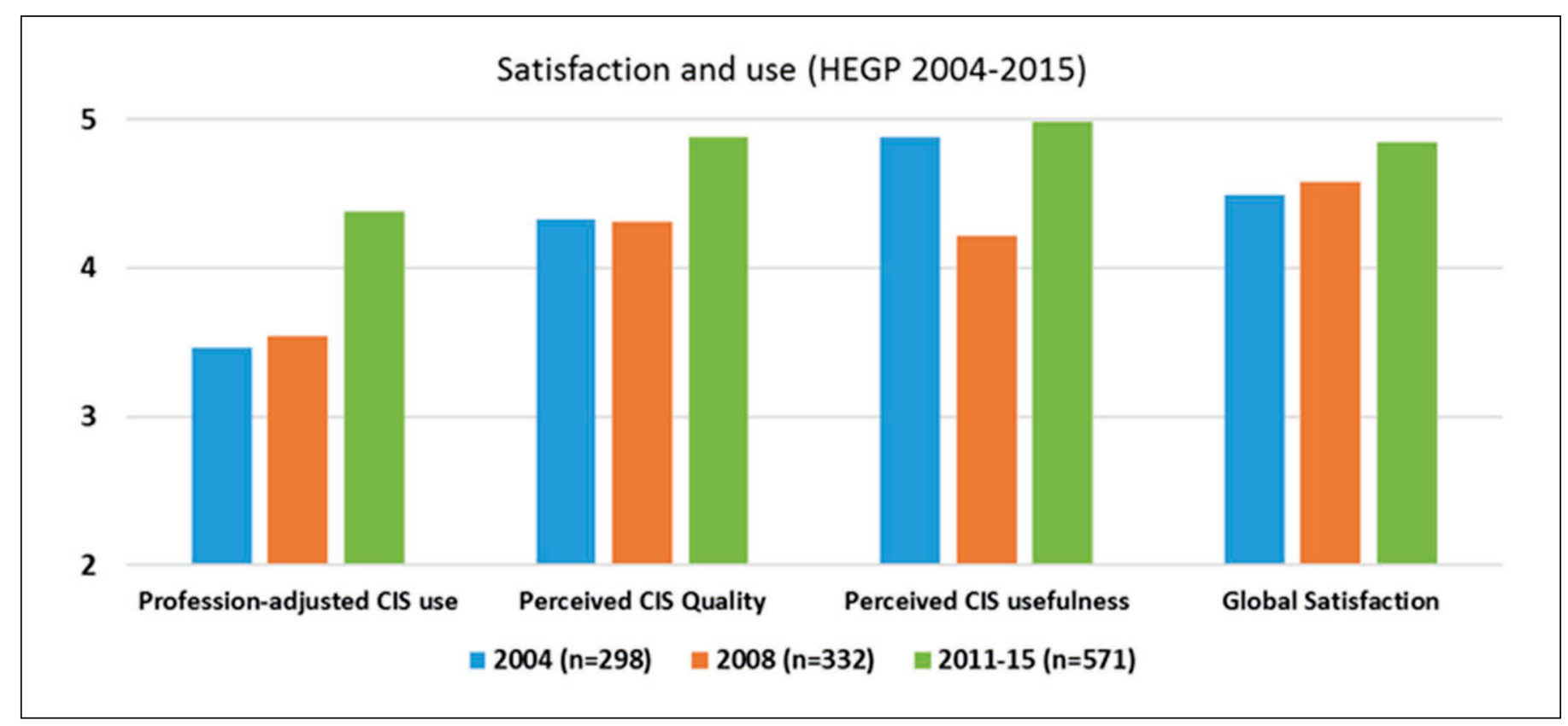

Fig. 3 Evaluation of CIS main acceptance dimensions during three successive phases at HEGP. Self-reported use and acceptance dimensions are evaluated on 1-7 Likert scales. 
A significant increase in CIS use was observed between 2004 and 2015, while overall user satisfaction increased regularly, even in the very late post adoption period (2011-2015), as showed in Figure 3.

In multiple regression analysis and structural equation models [15, 23], the bi-directional relationship between satisfaction and use was significant in the early deployment phase (4 years) but disappeared in the late ( 8 years) and very late phases (> 10 years). In a meaningful use situation, all users access the CIS whether satisfied or not with their CIS. Disappearance of the expected virtuous loop between user satisfaction and CIS use could indeed be considered as a sign of CIS maturity. It then becomes possible to test the other CIS use-related virtuous circles.

\section{The Use-Financial Efficiency Circle}

Most requests for proposals integrate a ROI chapter and CIS vendors are eager to find among their clients and/or in the literature positive financial evidence to promote their products. As others, we believe that these returns are overestimated and biased [24, 25]. Major limitations of financial efficiency studies are summarized here.

The context of the underlying health system (e.g., insurance coverage and reimbursement policies) is a key determinant in the choice of the financial model to be selected. Studies within different contexts and focusing on different beneficiaries are unlikely to provide the same results. For example, decreased utilization of care is an expected result of IT implementation from a national policy point a view. In a fee for service environment, decreased utilization should enter in the negative column for a hospital or practice charging for services. Efficient claim recovery is positive for the hospital budget but has a negative effect on overall health expenses. Reductions in length of stays are commonly associated with increased financial efficiency but when too drastic with increased external costs (e.g., rehabilitation, home care) and/or increased readmission rates. For example the potential US\$79 - 81 billion yearly savings expected from inter-operable EHR systems [5] may have disappeared in the fast increase of national health expenditures associated with the major coverage expansion under the Affordable Care Act [26].

Most earliest economic studies (e.g., before 2005) report on a small number of institutions with self-developed systems progressively adapted over long periods of time. On the contrary, most recent deployments rely on a limited number of commercial systems and much aggressive deployment strategies (1-3 years) [27]. Adaptations to local organization and work-flow management become more and more problematic as the number of clients increases or lead to unfair "site-specific adaptation" costs from the vendors.

Evaluations performed in selected units or on CIS subsystems (e.g., on CPOE, Electronic Medication Administrative Records (eMAR) or CDSSs), are at high risk of selection bias. A HIS is more than the sum of its parts and a hospital more than the set of its units. Benefits, if they exist, are likely to be found in advanced levels of IT deployment and/ or HIS integration (e.g., HIMSS/EMRAM levels 6 and 7) [8, 28]. They are also related to improved communication both within the institution and outside (e.g., practitioners, rehabilitation facilities, home care). In Bassi's review of 33 HIT economic evaluation papers, only four papers focused on full institutional information systems [10] among which one was considered negative [27].

Monetizing non-monetary variables (e.g., transforming into monetary units the reduction of a medical intervention side effects) as done in many cost-benefit or cost-consequences analysis $[8,10]$ is the most hazardous strategy. Accumulation of variables is not a criterion of quality and leads to increasingly complex models without taking into account the strong intra-correlations within the models' variables. For example, cost reductions associated with the reduction of side effects of drugs and those related to malpractice do not cumulate but should be combined with the increased costs associated with the e-iatrogenesis or the increased physicians' workload when using CPOE or documenting EHRs [30-33].

The limitation of the traditional accounting methods was a strong incentive for us to introduce econometric modeling approaches to evaluate the IT effect on hospital financial efficiency. The methods basically contrast a limited number of resources, considered as productivity inputs (e.g., number of beds, technological capital, labor expenses) with activity outcomes considered as productivity outcomes [34, 35]. Major econometric modeling techniques include Cobb-Douglas and Translog production functions, data envelopment analysis (DEA), and stochastic frontier analysis (SFA) [37, 38]. IT expenses can be entered either as variables within the productivity inputs or as moderating factors in the equation relating inputs and outputs [39].

In a preliminary study using Cobb-Douglas production functions conducted within 17 acute-care hospitals of AP-HP including HEGP, we observed a positive and significant relationship between IT investments (including capital and labor) and hospital productivity over an 8-year period (1998-2005) [34]. Results also showed that the benefits expected from the investments made were directly related to the integration level of the HIS: the higher the integration level, the greater the benefits. On a larger dataset (21 APHP acutecare hospitals, 1998-2006), both HIT and non-HIT inputs had a positive and significant impact on hospital productivity [39]. 2006 financial results were forecast from the 1998 to 2005 dataset with an accuracy of $99.4 \%$. But proving that HIT expenses significantly contribute to financial outcome is not sufficient when the objective is to demonstrate that increasing CIS use will be associated with an increased financial efficiency. In a more recent dataset (2009-2013, 20 acute-care AP-HP hospitals), cost-efficiency scores in a SFA model including 4 inputs (bed number, medical staff expenses, other personnel's expenses, and non-labor expenses) and one output (hospital financial income including outpatient visits, DRG-related income, and research-associated income) were found to diminish by $0.5 \%$ per year in a period where CIS use had definitively increased (figure 4). Interestingly, efficiency started out at a higher level and the reduction in efficiency was lower in the three hospitals with the highest IT maturity level, a difference of magnitude similar to the one observed between pediatric and non-pediatric hospitals. These results show the importance of a more comprehensive approach to the analysis of the CIS use-financial efficiency loop than the ones currently used. 


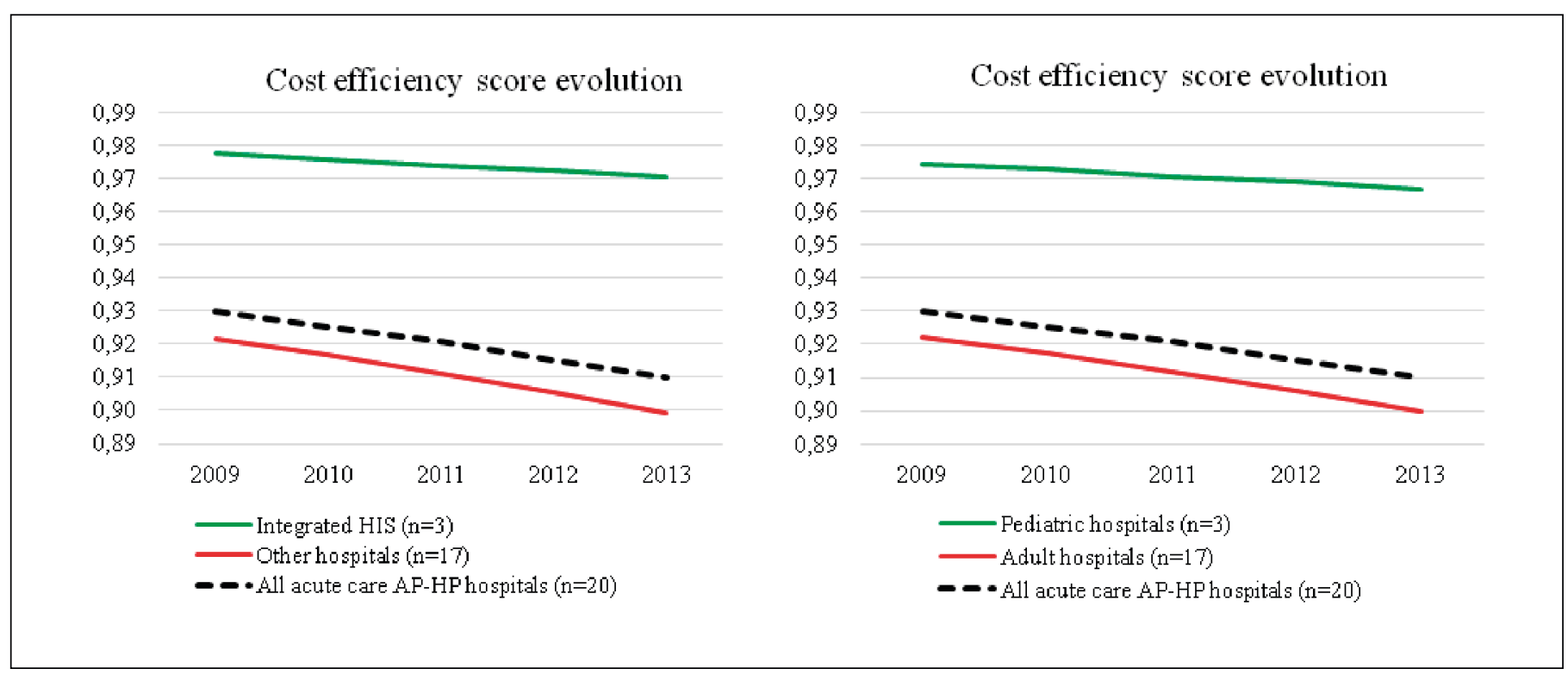

Fig. 4 Cost efficiency score evolution for 20 APHP acute care hospitals during the period 2009-2013.

\section{The Use-Quality Circle}

Major expected benefits are associated with the IT-related improvements of processes. They mainly rely on adherence with guidelines, in particular in the field of preventive health care delivery, or on the reduction of iatrogenesis through the implementation of adequate protocols (e.g., prevention of post-operative infections and pulmonary embolisms, pressure ulcers, or falls) [7]. The general use of ePrescription within EHR/CPOE facilitates professional adherence with rules of good medical practice (i.e., clinical alignment) and has been associated with a reduction of drug or diagnostic test-related iatrogenesis [40-41]. Inpatient mortality is the most commonly used outcome indicator: a negative correlation was observed by Beard et al. in a set of more than 2,000 US hospitals [28].

Development of clinical data warehouses (CDWs) fed from the running CIS can foster the production of such quality indicators. CDWs appear within the HIMSS EMRAM maturity level $7[3,42]$. Directly querying the operational CIS database is considered to generate a risk to the smooth functioning of the CIS [43]. Querying a mirrored database is less prone to side effects but requires an in-depth knowledge of the complexity of the production model. Most CDWs can be easily queried to provide the required quality indicators.

In addition, the CDW can serve clinical and translational research when phenotype and "omics" data are integrated (e.g. patient selection in the context of a more personalized practice of medicine) [44-46]. In the pharmaceutical domain at HEGP, the EHR/CDW integration was found invaluable in the evaluation of the frequency of both drug prescription and drug dispensing errors [47-48], the impact of alerts on drug dosage adjustment [49], the role of pharmacy drug order validation [50], but also to automatically detect drug-drug interactions [51] or to perform in-silico evaluations of decision rules for further integration into the operational environment of the CPOE [52].

Despite some indications of IT-related improved quality indicators, true outcome quality benefits that would bring evidence to the use-quality virtual cycle are unlikely to be obtained in a near future in the hospital context. Here are some explanatory reasons.

As stated by Riskin et al. "while there is a broad agreement that quality is important, national discussions seldom focus on what is actually measured and how those measurements are used" [25]. Most efforts have concentrated on processes (e.g., hemoglobin A1 measurements for diabetic patients) instead of outcome measures (e.g., the reduction of diabetes-associated complications) which should constitute the real target of health IT systems and of any quality improvement effort. Quality measures used by Welch et al., Zhou et al., and Acker et al. are process-based measures and improving processes does not guarantee outcomes are improved [54-56]. An appropriate strategy to validate the use-quality virtuous loop needs to be found to quantify the possible bidirectional relationship between processes and outcomes. IT can then be reintroduced as a moderating factor of this relationship in a more comprehensive model like the one proposed in figure 6 .

Most results of IT-quality studies mainly derive from outpatient environments and not from hospital environments [54-56]. Within hospital environments, results can be biased by the over-representation of a few academic centers [7], the partial selection of clinical units or pieces of the entire information system such as CDSS or CPOE components instead of the entire information system [40-41, 57-58]. 


\section{Production environment}

\section{Evaluation/Research environment}

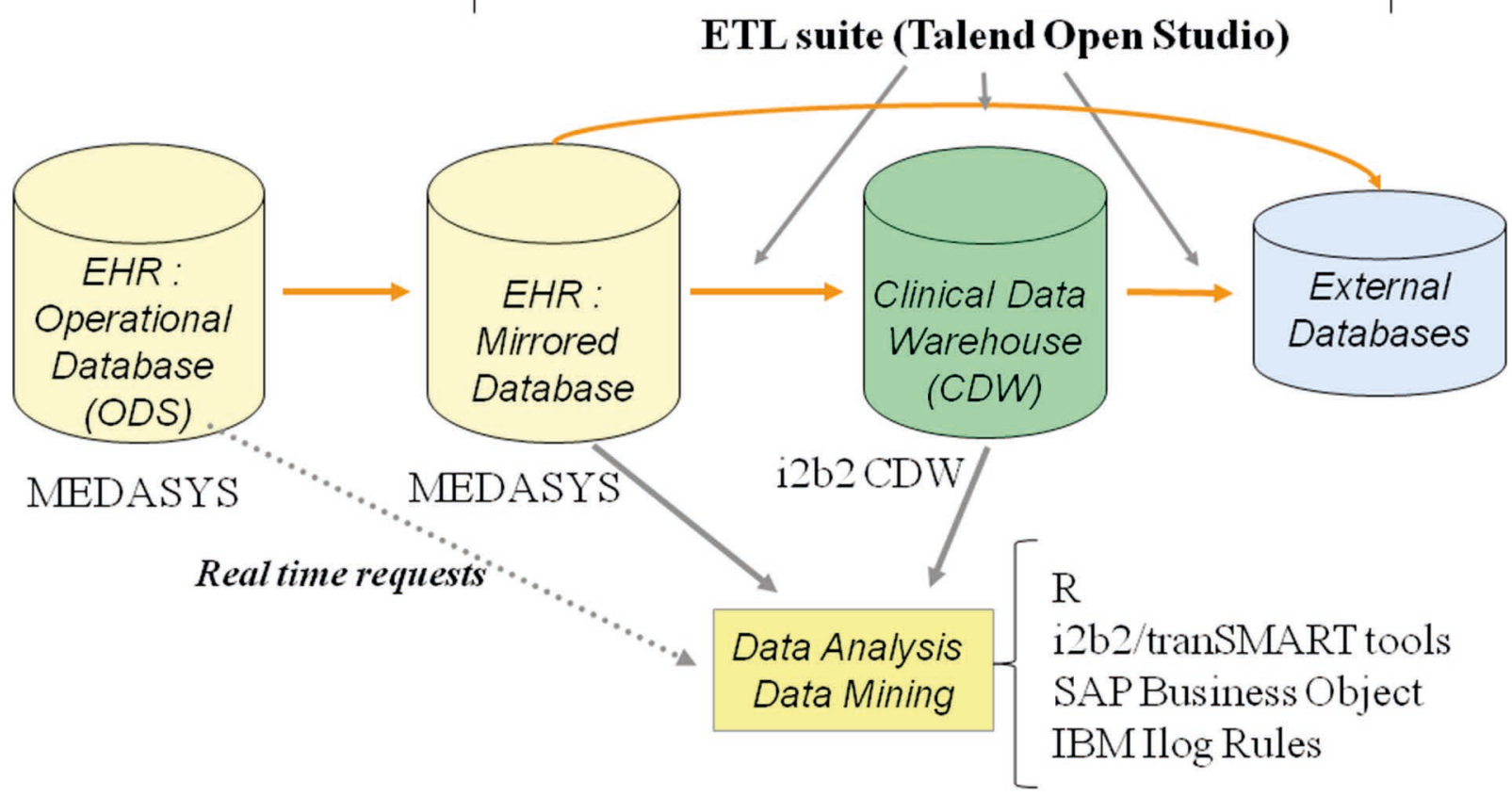

Fig. 5 Clinical Data Warehouse (CDW) at HEGP integrating i2b2 for phenotype data and transSMART for "omics" data.

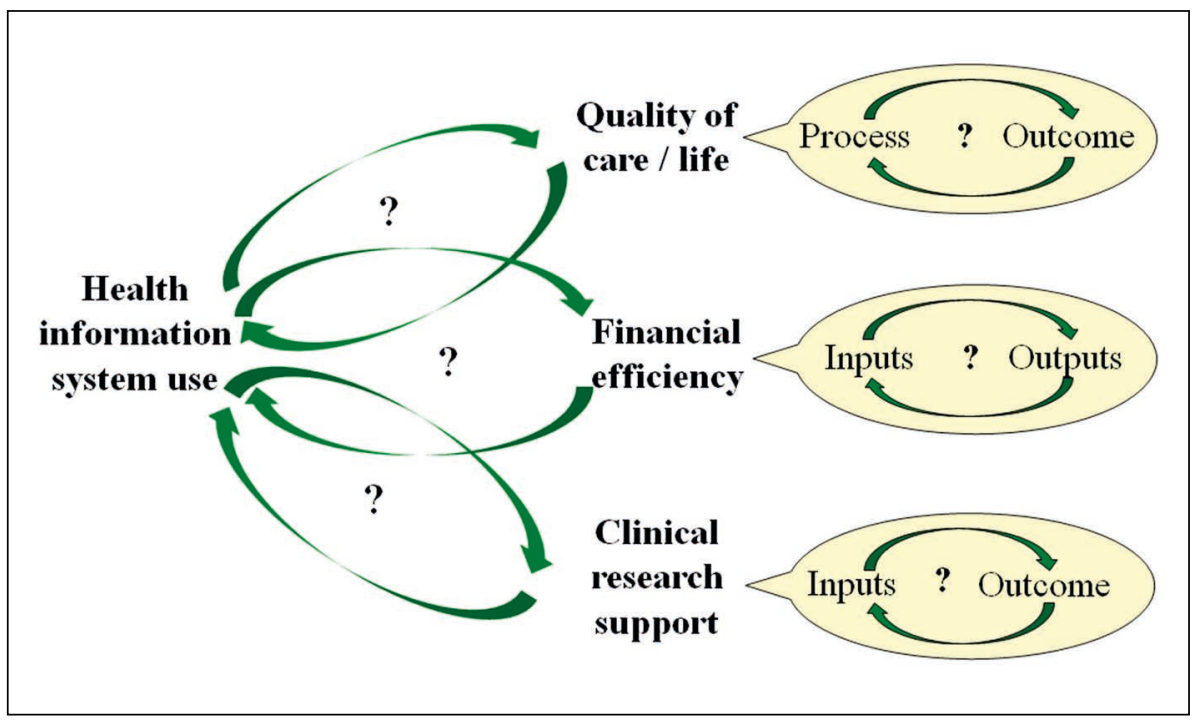

Fig. 6 A multi-step approach to the evaluation of the impact of information systems on targeted outputs or outcomes. The right column represents additional virtuous circles within the targeted objectives.
Reduction of medical iatrogenesis is a major quality objective. Many complications (e.g., per-operative mortality) may have a iatrogenic determinant but they may also correspond to the natural evolution of a disease given a current quality of care. Temporal series, adjusted to the severity of cases and performed in multi-center environments are more adapted to answer the question of the IT use - quality virtuous circle than just pre/post studies. Complications observed just after patient discharge (i.e., mortality, morbidity) are likely to be linked to the inpatient condition. In a broader view, when dealing with chronic conditions, answers to the outcome quality question fall clearly outside the brief periods of inpatient care. Examples are the control of hypertension or diabetes and the prevention of secondary complications, the long term evolution of cancers, and all the factors associated with the quality of life [53]. Answering quality questions requires the integration of hospital- produced data with data from disease registries or population-based databases. 


\section{Discussion and Conclusion}

International and national incentives have had a strong effect on the adoption and use of EHRs and associated CPOE and CDSS components both within and outside the hospital environment $[3,60]$. In place IT systems can automatically provide data that were only obtained through time-consuming manual chart reviews in the pre-IT era [6061]. Time has come where the virtuous loops that supported IT solution development and marketing can be tested against evidence from the real life. Examples given in this paper from the HEGP and AP-HP contexts and a necessary biased literature support the idea that the three virtuous loops examined here are part of our current utopia vision. The first one (satisfaction-use) will belong to history when all hospitals will have reach a MU IT level because bilateral relationships were only observed during the initial phase of IT development. The second loop (CIS use-financial efficiency) might melt in the historical context of drastic measures to reduce the cost of care because there is only partial evidence of an IT use - financial efficiency loop. The third one (CIS use-quality of care) is hard to demonstrate because the interesting results on care outcome are likely to be found outside the highly restricted context of hospital care

Methods for measuring system use are crucial and need to be standardized to facilitate multi-institutional benchmarking. Methods should address the granularity of the covered functions, the scales for self-reported system use as well as direct measurements from information systems, and finally the way to combine them into more general CIS use and maturity indicators.

Financial indicators should be clearly separated from quality indicators, as in figure 6 , to facilitate the interpretation of results, and when necessary they may be recombined in a secondary step into more complex explanatory models. In the financial domain, standardized metrics to measure the different input and output variables including the IT dependent ones are necessary.

In the quality domain, outcome measures should not only rely on process measures, such as the adherence with guidelines, which does not represent the final target of care and has the two major drawbacks of changing quickly with medical knowledge and being highly context-dependent. Interactions with emerging regional and national data warehouses should allow to fill the gap between intra and extra hospital data and pave the way to the larger utopian virtuous loops of global health information systems and better quality of life.

\section{Acknowledgments}

We are grateful to many colleagues at Paris Descartes University and former $\mathrm{PhD}$ students for the lively discussions around the ideas presented here and the provision of the raw data at their origin, in particular A. Boussadi, A. Burgun, P. Durieux, B.Hadji, S. Mellikeche, J. Ménard, R. Meyer, JM Palm, and B. Sabatier. This paper was edited based on a very fruitful discussion with the Yearbook editors, in particular C.U. Lehmann and Brigitte Séroussi, who we thank greatly.

\section{References}

1. Degoulet P. Success criteria for a clinical information system. In: TIC Saude 2013/ ICT in Health 2013. Brazilian Internet Steering Committee: Sao Paulo; 2014. p. 235-42.

2. Degoulet P. Hospital Information Systems. In: Venot A, Burgun A, Quantin C (eds). Medical Informatics, e-Health. Paris: Springer-Verlag; 2014. p. 289-313.

3. HIMSS Analytics 2015. [http://www.himssanalytics.org/home/index.aspx]

4. ONC 2013 [http://www.healthit.gov/providers-professionals/how-attain-meaningful-use]

5. Hillestad R, Bigelow J, Bower A, Girosi F, Meili $\mathrm{R}$, Scoville R, et al. Can electronic medical record systems transform health care? Potential health benefits, savings, and costs. Health Aff(Millwood) 2005;24(5):1103-17.

6. Walker J, Pan E, Johnston D, Adler-Mistein J, Bates D, Middleton B. The value of health care information exchange and interoperability. Health Aff (Millwood) 2005 Jan-Jun;Suppl Web Exclusives:W5-10-W5-18.

7. Chaudry B, Wang J, Wu S, Maglione M, Mojica W, Roth E, et al. Systematic review: Impact of health information technology on quality, efficiency, and costs of medical care. Ann Intern Med 2006;144(10):742-52.

8. Meyer R, Degoulet P. Assessing the Capital Efficiency of Healthcare Information Technologies Investments: An Econometric Perspective: Yearb Med Inform 2008;114-27.

9. Payne T, Bates DW, Berner ES, Bernstam EV, Covvey $\mathrm{HD}$, Frisse ME, et al. Healthcare information technology and economics. J Am Med Inform
Assoc 2013;20: 212-217.

10. Bassi J, Lau F. Measuring value for money: a scoping review on economic evaluation of health information systems. J Am Med Inform Assoc 2013;20(2):792-801.

11. More T. De optimo rei publicae statu, deque nova insula Utopia "Of a republic's best state and of the new island Utopia". Louvain: Thierry Martens; 1516.

12. Degoulet P, Marin L, Lavril, Le Bozec C, Delbecke E, Meaux JJ, et al. The HEGP component-based clinical information system. Int J Med Inform 2003;69:115-26

13. Ammenwerth E, Mansmann U, Iller C, Eichstadter R. Factors affecting and affected by user acceptance of computer-based nursing documentation: results of a two-year study. J Am Med Inform Assoc 2003;10:69-84.

14. Palm JM, Dart T, Dupuis I, Leneveut L, Degoulet P. Clinical information system post-adoption evaluation at the Georges Pompidou university hospital. AMIA Annu Symp Proc 2010;582-6.

15. Hadji B, Martin G, Dupuis I, Campoy E, Degoulet P. 14 Years longitudinal evaluation of clinical information systems acceptance. Int J Med Inform 2016;86:20-9.

16. Hadji B, Degoulet P. Information sytem end-user satisfaction and continuance intention: A unified modeling approach. J Biomed Inform 2016;61:185-93

17. DeLone WH, McLean ER. The DeLone and McLean Model of Information Systems Success: A Ten-Year Update. Journal of Management Information Systems 2003;19c(4):9-30.

18. Petter S, McLean ER. A meta-analytic assessment of the DeLone and McLean IS success model: An examination of IS success at the individual level. Information \& Management 2009;46(3):159-66.

19. Davis F. Perceived usefulness, perceived ease of use, and user acceptance of information technology. MIS Quarterly. 1989;13:319-40.

20. Lee YA, Kozar KA, Larsen KRT. The Technology Acceptance Model: Past, Present and Future. Comm Assoc Inf Syst 2003;12(50):752-80.

21. Venkatesh V, Morris M, Davis G, et al. User Acceptance of Information Technology: Toward a Unified View. Manag Inf Syst Q 2003;27:425-78.

22. Bhattacherjee A. Understanding information systems continuance: an expectation-confirmation model. MIS Quarterly 2001;25(3):351-70.

23. Kline RB. Principles and practice of structural equation modeling. Guilford Press; 2011.

24. Sidorov J. It ain't necessarily so: the electronic health record and the unlikely prospect of reducing health care costs. Health Aff (Millwood) 2006; 25(4):1079-85.

25. Riskin L, Koppel R, Riskin D. Re-examining health IT policy: what will it take to derive value from our investments? J Am Med Inform Assoc 2015;22:459-64.

26. CMS 2016. National expenditures 2014 highlights. Available at [https://www.cms.gov/ Research-Statistics-Data-and-Systems/Statistics-Trends-and-Reports/NationalHealthExpendData/Downloads/highlights.pdf] [accessed January 5, 2016]

27. Koppel R, Lehmann CU. Implications of an emerging EHR monoculture for hospitals and 
healthcare systems. J Am Med Inform Assoc 2015;22(2):465-71.

28. Beard N, Elo K, Hitt LM, Housman MG, Mansfield $\mathrm{G}$. Information technology and hospital performance: An econometric analysis of costs and quality. PricewaterhouseCoopers; 2007. [http://assets.wharton.upenn.edu/ housman/files/ PwCWhitePaper.pdf]

29. Furukawa MF, Raghu TS, Shao BB. Electronic medical record and cost efficiency in hospital medical-surgical units. Inquiry 2010;20:110-23.

30. Weiner JP, Kfuri T, Chan KC, Fowles JB. e-Iatrogenesis: the most critical unintended consequence of CPOE and other HIT. J Am Med Inform Assoc 2007; $14: 387-88$

31. Koppel R, Metlay JP, Cohen A, Abaluck B, Localio AR, Kimmel SE, et al; Role of Computerized Physician Order Entry Systems in Facilitating Medication Errors; JAMA 2005;293(10):1197-203.

32. Ash JS, Sittig DF, Poon EG, Guappone K, Campbell E, Dykstra RH. The extent and importance of unintended consequence elated to computerized provider order entry. J Am Med Inform Assoc 2007;14(4):415-23.

33. Poissant L, Pereira J, Tamblyn R, Kawasumi Y. The impact of electronic health records on time efficiency of physicians and nurses: a systematic review. J Am Med Inform Assoc 2005;12(5):505-16.

34. Meyer R, Degoulet P, Omnes L. Impact of Health Care Information Technology on Hospital Productivity Growth: a Survey in 17 Acute University Hospitals. Stud Health Technol Inform 2007;129 (Pt1):203-7.

35. Hadji B, Meyer R, Mellikeche S, Escalon S, Degoulet $\mathrm{P}$. Assessing the relationships between hospital resources and activities: a systematic review. J Med Syst 2014;38-127.

36. Farrell MJ. The Measurement of Productive Efficiency. J R Stat Soc Ser Gen 1957;120:253-90.

37. Aigner D, Lovell CAK, Schmidt P. Formulation and estimation of stochastic frontier production function models. J Econom 1977;6:21-37.

38. Rosko MD, Mutter RL. Stochastic frontier analysis of hospital inefficiency. A review of empirical issues and an assessment of robustness. Med Care Res Rev 2008;65(2):131-66.

39. Meyer R, Degoulet P. Choosing the right amount of healthcare information technologies investments. Int J Med Inform 2010;79:235-31

40. Kauskal R, Shojania KG, Bates DW. Effects of computerized physician order entry and clinical decision support systems on medication safety. A systematic review. Arch Intern Med 2003;163:1409-16.

41. Garg AX, Adhikari NKJ, McDonald H, Rosas-Arellano MP, Devereaux PJ, Beyene J, et al. Effects of computerized clinical decision support systems on practitioner performance and patient outcome. A systematic review. JAMA 2005;293(10):1223-38.

42. Murphy SN, Weber G, Mendis M, Chueh HC, Churchill S, Glaser JP, et al. Serving the Enterprise and beyond with Informatics for Integrating Biology and the Bedside (i2b2). J Am Med Inform Assoc 2010;17(2):124-30.

43. Zapletal E, Rodon E, Grabar N, Degoulet P. Methodology of integration of a clinical data warehouse with a clinical information system. Stud Health Technol Inform 2010;160(Pt 1):193-7.

44. Kho AN, Rasmussen LV, Connolly JJ, Peissig PL, Starren J, Hakonarson H, et al. Pratical challenges in integrating genomic data into the electronic health record. Genet Med 2013;15(10):772-8.

45. Canuel V, Rance B, Avillach P, Degoulet P, Burgun A. Translational Research Platforms Integrating Clinical and Omics Data: a Review of Publicly Available Solutions. Brief Bioinform 2015;16(2):280-90

46. Rance B, Canuel V, Countouris H, Laurent-Puig P, Burgun A. Integrating Heterogeneous Biomedical Data for Cancer Research: the CARPEM infrastructure. Appl Clin Inform 2016;7(2):260-74.

47. Caruba T, Colombet I, Gillaizeau F, Bruni V, Korb $\mathrm{V}$, Prognon P, et al. Chronology of prescribing error during the hospital stay and prediction of pharmacist's alerts overriding: a prospective analysis. BMC Health Serv Res 2010 Jan 12;10:13.

48. Berdot S, Sabatier B, Gillaizeau F, Caruba T, Durieux P. Evaluation of drug administration errors in a teaching hospital. BMC Health Serv Res 2012; 12:60.

49. Sellier E, Colombet I, Sabatier B, Breton G, Nies $\mathrm{J}$, Zapletal E, et al. Effect of alerts for drug dosage adjustments in inpatients with renal insufficiency. J Am Med Inform Assoc 2009; 16:203-10.

50. Estellat C, Colombet I, Vautier S, Huault-Quentel, Durieux P, Sabatier B. Impact of pharmacy validation in a computerized physician order entry context.Int J Qual Health Care 2007;9(5):317-25.

51. Girardeau Y, Trivin C, Durieux P, Le Beller C, Louet Agnes LL, et al. Detection of Drug-Drug Interactions Inducing Acute Kidney Injury by
Electronic Health Records Mining. Drug Saf 2015;38(9):799-809.

52. Boussadi A, Caruba T, Zapletal E, Sabatier B, Durieux P, Degoulet P. A clinical data warehouse-based process for refining medication orders alerts. J Am Med Inform Assoc 2012;19(5):782-5.

53. McDowell I. Measuring Health. 3rd Edition. New York: Oxford University Press; 2006.

54. Welch WP, Bazarko D, Ritten K, Burgess Y, Harmon R, Sandy LG. Electronic health records in four community physician practice: impact on quality and cost of care. J Am Med Inform Assoc 2007; 14:320-8

55. Zhou L, Soran C, Jenter CA, Volk LA, Orav EJ, Bates DW, et al. The relationship between electronic record use and quality of care over time. J Am Med Inform Assoc 2009;16(4):457-64.

56. Ancker JA, Kern LM, Edwards A, et al. Association between healthcare quality and use of electronic health record functions in ambulatory care. J Am Med Inform Assoc 2015;22:864-71.

57. Mekhjian, Kumar RR, Kuehn L, BentleyTD, Teater $\mathrm{P}$, Thomas A, et al. Immediate benefits realized following implementation of physician order entry at an academic medical center. J Am Med Inform Assoc 2002:9:529-39.

58. Kuperman GJ, Gibson RF. Computer physician order entry: benefits, costs, and issues. Ann Intern Med 2003;139:31-9.

59. Wright A, Feblowitz J, Samal L, McCoy B, Sittig DF. The Medicare electronic health record incentive program: provider performance on core and menu measures. Health Serv Res 2014;49(1 Pt 2):325-46.

60. Roski J, McClellan M. Measuring health care performance now, not tomorrow; essential steps to support effective health reform. Health Aff (Millwood) 2011;30:682-9.

61. Garrido T, Kumar S, Lekas J, Lindberg M, Kadiyala D, Whippy A, et al. e-Measures: insight into the challenges and opportunities of automating publicly reported quality measures. J Am Med Inform Assoc 2014;21:181-4.

Correspondence to:

Patrice Degoulet

Laboratoire de Santé Publique et Informatique Médicale

Faculté de Médecine René Descartes et INSERM

15 , rue de l'Ecole de Médecine

75006 Paris, France

E-mail: patrice.degoulet@aphp.fr 